\title{
WILLIAM PEDDIE
}

William Peddie occupied the Harris Chair of Physics at University College, Dundee, in the University of St Andrews, from 1907 to 1942. He died at his home, "The Weisha," Ninewells, on June 2nd, 1946, having completed the eighty-fifth year of his life on May 31st. He was born in a Free Church Manse in Papa Westray, one of the northmost of the Orkney Islands.

Peddie's interest in science and philosophy was both wide and deep. His First Year course at Dundee, which was attended by all Science students and many Arts students besides, was developed from the philosophic viewpoint.

During his tenure of the chair his main contributions to science were in the fields of Colour Vision and Molecular Magnetism, and he wrote textbooks intended for Honours students on both subjects. He has been described as the leading exponent of the Young-Helmholtz trichromatic theory of colour vision. The subject is common ground for physicists, physiologists and psychologists, and the trichromatic theory has from time to time come under attack from all sections. Helmholtz's work was least satisfactory where it was concerned with differential sensitivity. His fundamental assumptions were at variance with the subsequently discovered law of Abhey that the intensity of a composite colour is the arithmetic sum of the intensities of its components. In 1920 Schroedinger showed how the necessary adjustment in Helmholtz's work could be made. Thereafter Peddie regarded the establishment of the trichromatic theory as complete.

Peddie's work in Magnetism lay in the development of the work of Weber, Ewing, Weiss and others, particularly with reference to magnetic quality in crystals.

Peddie's earlier work was done in Edinburgh. He entered the University as a student in 1880 . He became a pupil of P. G. Tait and shared with many of Tait's students a great and lasting admiration for the master.

Peddie became Tait's assistant and in 1892 was appointed Lecturer in Natural Philosophy; he held this post until he was appointed to the Harris Chair. He was elected a Fellow of the Royal Society of Edinhurgh in 1887, and graduated D.Sc. in 1888 . The R.S.E. awarded 
him the Makdougall-Brisbane prize for his work on the torsional rigidity of wires.

When the Edinburgh Mathematical Society was founded in 1882 Peddie, then a student, joined it. The following year he became a member of the Committee, and he was elected President in 1896, having edited the Proccedings for two years in the interval. Peddie was again chosen as President in the Society's fiftieth session, a fitting choice which cnsured that he as one of the foundation members should preside at the Jubilee Dinner on February 3rd, 1933.

He published several papers in the Society's Proceedings and Mathematical Notes, the first being "On the fundamental principles of cuaternions, with other vector analyses" (1893), and the last "A geometrical construction with physical applications" (Notcs, 1933). Other titles were "On the uniqueness of the solution of the linear cifferential equation of the second order" (1903) and "The condition for the reality of the roots of an $n$-ic" (1906). He also contributed many papers at the Society's meetings on such subjects as "Reflected rainbows", "Theory of contours and applications to physical science" and "On the foundations of dynamics".

All who came in contact with Peddie will agree in paying the highest tribute to his personal qualities. To have his friendship was a privilege. It was a great pleasure to accompany him on a drive along the valleys and through the passes of the Sidlaw Hills with perhaps a risit to a bird sanctuary, where in his modest way he would unfold his great knowledge of bird life.

Sorrow came to him through the long illness and death in 1927 of his much loved wife. With advancing years he lost his hearing completely and the last sounds he heard were the songs of the birds in his garden long after he ceased to hear the human voice. But eren then he would entertain his visitors with reminiscences of his boating adrentures in the waters around Orkney, or of his early days in Edinburgh; and he always maintained a vital interest in his own subject. His conversation was always stimulating and his personality communicated a sense of peace and calm. He was the gentlest, the kindest and most delightful of men.

Raymond SMart. 